\title{
The de Winter Electrocardiographic Pattern: What Else do we need to Learn?
}

\author{
Yalcin Velibey, Duygu Genç, Duygu Inan, Ozan Tezen \\ Department of Cardiology, Siyami Ersek Thoracic and Cardiovascular Surgery Center, Training and Research Hospital, Istanbul, Turkey \\ ORCID: \\ Yalcin Velibey: https://orcid.org/0000-0001-7075-2011 \\ Duygu Genç: https://orcid.org/0000-0002-5865-5873 \\ Duygu Inan: https://orcid.org/0000-0003-3921-6469 \\ Ozan Tezen: https://orcid.org/0000-0002-2774-8348
}

\section{Abstract}

Electrocardiographic (ECG) abnormalities are often indicative of acute coronary artery occlusion. Early detection of these abnormalities is important for the identification of patients who may be candidates for emergent percutaneous coronary revascularization (PCR). In most cases, ST-segment elevation is the key factor in selecting patients for PCR. However, some cases with acute coronary artery occlusion do not have ST-segment elevation, resulting in delays in coronary reperfusion treatment. A 37-year-old male presented to the emergency department with typical chest pain. The patient indicated that he was a heavy marijuana user. Even though his admission ECG did not reveal ST-segment elevation, he was hemodynamically stable, and he did not develop life-threatening arrhythmias, he was immediately taken to the catheterization laboratory for urgent angiography with the diagnosis of acute myocardial infarction. The occluded left anterior descending artery seen in angiography was successfully revascularized with percutaneous coronary intervention. Herein, we present a case of a patient who was admitted to the emergency department with chest pain and ECG demonstrating the de Winter pattern. Based on this case, we present a detailed evaluation regarding the de Winter ECG pattern, which is equivalent to ST-segment elevation.

Keywords: Acute left anterior descending coronary artery occlusion, de Winter pattern, electrocardiography, primary percutaneous coronary intervention

\section{INTRODUCTION}

In the absence of overt ST-segment elevation, there are several other electrocardiographic (ECG) patterns that can indicate a need for emergent revascularization. The literature terms these patterns as ST-elevation myocardial infarction (STEMI) equivalents. ${ }^{[1]}$ The present case illustrates the importance of recognizing the de Winter ECG pattern as a STEMI equivalent in cases with suspected acute myocardial infarction. The current guidelines indicate ST-segment elevation as the primary indication for emergent revascularization. However, as a STEMI equivalent, the de Winter ECG pattern is equally important and should be promptly recognized in the emergency

Submission: 27-Jan-19 Revision: 28-Mar-19 Accepted: 29-Mar-19
Video Available on: http://www.ijcva.com
Access this article online
Quick Response Code:

department as it indicates an immediate need for emergent revascularization.

\section{Case Report}

A 37-year-old male with no previous medical history presented to the emergency department with typical chest pain for $2 \mathrm{~h}$. He said that he had been using marijuana two times/day for the past 10 years. On admission, his arterial blood pressure was $125 / 75 \mathrm{mmHg}$, and his heart rate was $74 \mathrm{bpm}$. Electrocardiography revealed marked ST-segment

Address for correspondence: Dr. Yalcin Velibey, Siyami Ersek Thoracic and Cardiovascular Surgery Center, Training and Research Hospital, Department of Cardiology, Tibbiye Str. No: 25, Uskudar, Istanbul, Turkey. E-mail: dr_yalchin_dr@yahoo.com.tr

This is an open access journal, and articles are distributed under the terms of the Creative Commons Attribution-NonCommercial-ShareAlike 4.0 License, which allows others to remix, tweak, and build upon the work non-commercially, as long as appropriate credit is given and the new creations are licensed under the identical terms.

For reprints contact: reprints@medknow.com

How to cite this article: Velibey Y, Genç D, Inan D, Tezen O. The de winter electrocardiographic pattern: What else do we need to learn?. Int J Cardiovasc Acad 2019;5:103-5. 
depression of up to $2 \mathrm{~mm}$ after the $\mathrm{J}$ point, hyperacute T-waves in derivations V3-V6, and ST-segment depression of $0.5 \mathrm{~mm}$ in the inferior leads [Figure 1]. After being given a loading dose of clopidogrel $(600 \mathrm{mg})$ and acetylsalicylic acid $(300 \mathrm{mg})$, he was taken to the catheterization laboratory for emergent coronary angiography. Angiography revealed a $98 \%$ thrombotic stenosis at the proximal portion of the left anterior descending artery (LAD) [Figure 2a] and plaques in the circumflex and right coronary arteries without significant stenosis. Therefore, following a bolus dose $(10 \mu \mathrm{g} / \mathrm{kg})$ of intravenous (IV) tirofiban, the patient successfully underwent balloon angioplasty (Invader $2 \mathrm{~mm} \times 15 \mathrm{~mm}, 16 \mathrm{~atm}$ ) with stenting (drug-eluting stent, Biomatrix $2.75 \mathrm{~mm} \times 24 \mathrm{~mm}$, $10 \mathrm{~atm}$ ) [Figure $2 \mathrm{~b}$ and Video 1]. The patient was then transferred to the coronary care unit, where he received IV tirofiban infusion $(0.1 \mu \mathrm{g} / \mathrm{kg} / \mathrm{min})$. An ECG recorded $90 \mathrm{~min}$ after the coronary revascularization revealed a sinus rhythm with complete resolution of the de Winter ECG pattern [Figure 3]. No bleeding, thrombotic, or ischemic events occurred during the hospitalization, and the patient was discharged from the hospital after 7 days.

\section{Discussion}

The eponymous ECG pattern was first described in 2008 by de Winter et al. in $2 \%$ of patients with acute anterior wall myocardial infarction. ${ }^{[2]}$ In 2009 , Verouden et al. demonstrated the de Winter ECG pattern in 35 of 1890 patients who underwent primary percutaneous coronary intervention (pPCI) for LAD artery obstruction. ${ }^{[3]}$ The de Winter ECG pattern consists of persistent 1-3-mm ST-segment depression at the J-point, upsloping ST segments that continue into tall, symmetrical T-waves in the precordial (V1-V6) leads, and slight ST-segment elevation in augmented vector right (aVR). In addition, ST-segment depression in the inferior leads is frequently seen in the de Winter ECG pattern. This pattern has positive predictive values of $95 \%-100 \%$ in the respective diagnostic studies. ${ }^{[4]} \mathrm{As}$ in the case described herein, patients with the de Winter ECG pattern are generally younger and more often male. Despite the presence of persistent LAD occlusion, it was initially thought that de Winter ECG pattern was a static condition that did not evolve into overt ST-segment elevation. ${ }^{[2,3]}$ However, it was later described that de Winter ECG pattern could evolve into ST-segment elevation in anterior derivations (consistent with STEMI) prior to coronary revascularization. ${ }^{[4,5]}$ On the other hand, Zhao et al. described two ECG patterns indicating that ST-segment elevation can evolve into the de Winter ECG pattern. ${ }^{[6]}$ Montero-Cabezas et al. indicated that Q-wave and/or ST elevation may occur in ECGs performed after successful coronary revascularization. ${ }^{[7]}$ Finally, in 2018, Tsutsumi and Tsukahara demonstrated the de Winter ECG pattern in the inferiolateral (II, III, aVF, and V4-V6) leads in a patient who underwent pPCI for right coronary artery obstruction. ${ }^{[8]}$ In the present case, the ECG recorded 90 min after successful coronary reperfusion revealed loss of the de

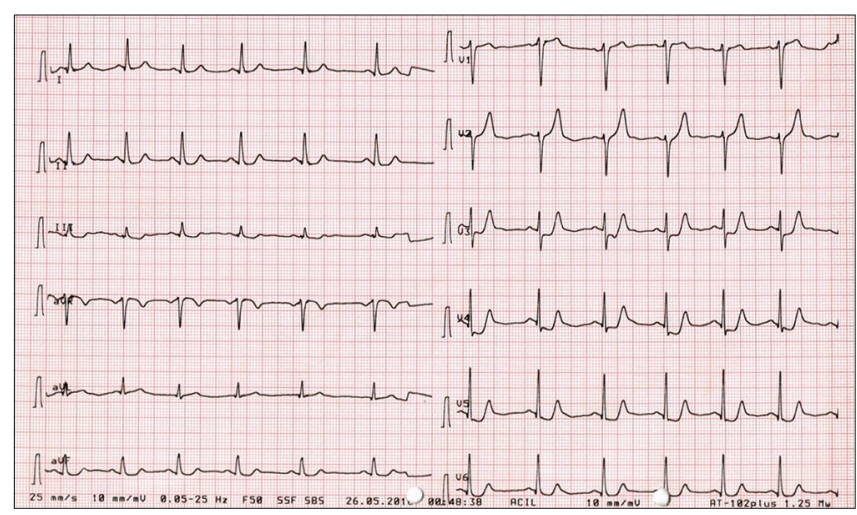

Figure 1: Electrocardiographic obtained in the emergency department showing marked ST-segment depression in leads V3-V6 and tall, symmetrical T-waves in the precordial leads

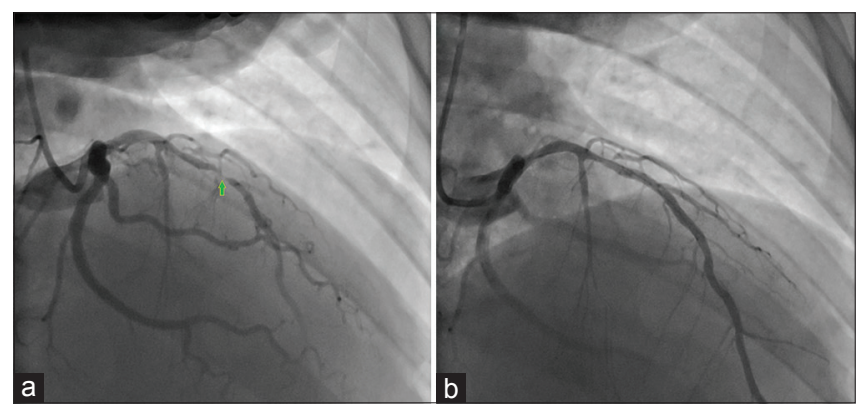

Figure 2: Selective left coronary angiography before (a) and after (a) emergent percutaneous coronary intervention. Coronary angiography showing subtotal occlusion at the proximal segment of left anterior descending (a). Coronary angiography showing left coronary artery after successful reperfusion followed by stent placement (b)

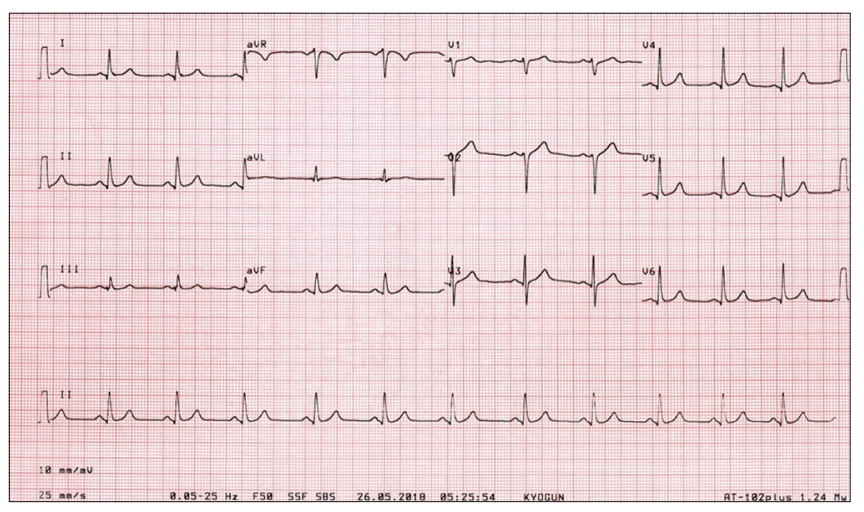

Figure 3: Electrocardiographic 90 min after coronary revascularization (left anterior descending stenting) showing resolution of the de Winter electrocardiographic pattern

Winter pattern without ST elevation. In light of the current case and published data, we believe that the de Winter ECG pattern can be divided into two subgroups as follows: (1) static pattern characterized by a J-point depression that persists until coronary revascularization and does not evolve into overt ST-segment elevation and (2) dynamic pattern that can evolve into ST-segment elevation (or vice versa) in the context of total occlusion or spontaneous recanalization. ${ }^{[3,7]}$ 
The exact electrophysiological mechanisms underlying these ECG changes are not exactly known. However, it has been hypothesized that defective sarcolemmal adenosine triphosphate-sensitive potassium channel activation is responsible for the absence of ST-segment elevation..$^{[9,10]}$ Another potential explanation is an anatomical variant of the Purkinje fibers with endocardial conduction delay. Moreover, some authors postulated that collateral blood supply might protect the myocardium from transmural ischemia and prevent ST-segment elevation, and others advocated that the area of transmural ischemia was so large that no injury currents were generated toward the precordial leads but only directed upward to an aVR lead. ${ }^{[8]}$

\section{Conclusion}

The de Winter ECG pattern is important to recognize because it is associated with subtotal or total obstruction of the proximal segment of the LAD artery and is considered a STEMI equivalent. Therefore, ambulance staff, emergency physicians, and cardiologists should be able to recognize the de Winter ECG pattern in addition to other ECG patterns that are considered to be STEMI equivalents, including Wellens syndrome, posterior ST-elevation myocardial infarction, Sgarbossa criteria in left bundle branch blocks, and ST elevation in lead aVR. We emphasize that although the current revascularization guidelines highlight ST-segment elevation as the principle indication for emergent revascularization, the de Winter pattern should also be recognized without delay, as it implies the same indications as ST-segment elevation.

\section{Declaration of patient consent}

The authors certify that they have obtained all appropriate patient consent forms. In the form the patient(s) has/have given his/her/their consent for his/her/their images and other clinical information to be reported in the journal. The patients understand that their names and initials will not be published and due efforts will be made to conceal their identity, but anonymity cannot be guaranteed.

\section{Financial support and sponsorship}

Nil.

\section{Conflicts of interest}

There are no conflicts of interest.

\section{RefERENCES}

1. Birnbaum I, Birnbaum Y. High-risk ECG patterns in ACS - Need for guideline revision. J Electrocardiol 2013;46:535-9.

2. de Winter RJ, Verouden NJ, Wellens HJ, Wilde AA; Interventional Cardiology Group of the Academic Medical Center. A new ECG sign of proximal LAD occlusion. N Engl J Med 2008;359:2071-3.

3. Verouden NJ, Koch KT, Peters RJ, Henriques JP, Baan J, van der Schaaf RJ, et al. Persistent precordial "hyperacute" T-waves signify proximal left anterior descending artery occlusion. Heart 2009;95:1701-6.

4. Goebel M, Bledsoe J, Orford JL, Mattu A, Brady WJ. A new ST-segment elevation myocardial infarction equivalent pattern? Prominent $\mathrm{T}$ wave and J-point depression in the precordial leads associated with ST-segment elevation in lead aVr. Am J Emerg Med 2014;32:287.e5-8.

5. Fiol Sala M, Bayés de Luna A, Carrillo López A, García-Niebla J. The "De winter pattern" can progress to ST-segment elevation acute coronary syndrome. Rev Esp Cardiol (Engl Ed) 2015;68:1042-3.

6. Zhao YT, Wang L, Yi Z. Evolvement to the de winter electrocardiographic pattern. Am J Emerg Med 2016;34:330-2.

7. Montero-Cabezas JM, van der Kley F, Karalis I, Schalij MJ. The "De winter pattern" can progress to ST-segment elevation acute coronary syndrome. Response. Rev Esp Cardiol (Engl Ed) 2015;68:1043.

8. Tsutsumi K, Tsukahara K. Is the diagnosis ST-segment elevation or non-ST-segment elevation myocardial infarction? Circulation 2018;138:2715-7.

9. Li RA, Leppo M, Miki T, Seino S, Marbán E. Molecular basis of electrocardiographic ST-segment elevation. Circ Res 2000;87:837-9.

10. Yang W, Liu H, Zhu M, Song Z. The de winter electrocardiographic pattern of proximal left anterior descending occlusion. Am J Emerg Med 2017;35:937. 